\title{
TITLE:
}

\section{Chimpanzee Research in the Ndoki Forest}

\author{
AUTHOR(S):
}

Takenoslzita, Yuji

\section{CITATION:}

Takenoslzita, Yuji. Chimpanzee Research in the Ndoki Forest. Pan Africa News 1996, 3(2): 7-8

\section{ISSUE DATE:}

1996-12

URL:

http://hdl.handle.net/2433/143342

RIGHT:

Copyright (c) Pan Africa News. 
Ed. note: The article below is by Yuji Takenoshita, a graduate student in the Department of Zoology, Kyoto University who returned this year from Congo where he conducted socio-ecological research on tschego chimpanzees (Pan troglodytes troglodytes) in the Ndoki Forest from September 1995 to May 1996. He kindly provided us with an update on the status of research by his team.

\section{Chimpanzee Research in the Ndoki Forest}

Yuji Takenoshita

Kyoto University

\section{1: Study site: Nouabalé-Ndoki National Park}

Nouabalé-Ndoki National Park (Ndoki) is located in the northern end of Congo, near the border between Cameroun, Central African Republic and Congo. The national park was established in 1993 and is managed by the Congolese government in cooperation with the Wildlife Conservation Society (WCS). For details of conservation 
activity in this area, see Nishihara and Fay (1).

The main site for my research is in the Guga section of the park where socio-ecological studies of chimpanzees and sympatric gorillas have been conducted by Japanese and Congolese researchers since 1994. Before studies began in this area research was conducted in an adjacent area, Djinji, from 1991 to 1993.

The main purpose of the chimpanzee study is to reveal the social structure of the tschego chimpanzees, with a special focus on the concept of the "unit group" (community). Relationships with other sympatric primate species found in the area, i.e. western lowland gorillas (Gorilla gorilla gorilla), guenons and colobus, are also targets for research.

\section{2: Status of chimpanzees observations}

During the 9 months encompassed by the study period I encountered chimpanzees, who were difficult to locate just by walking in the forest, only 65 times. When large trees like figs were fruiting, however, I was able to encounter them frequently by waiting near those trees.

The habituation of chimpanzees has unfortunately not been accomplished yet. In most cases chimpanzees became very agitated and interrupted their activities when they saw us. They were more tolerant to an observer's presence when we saw them at fruiting trees and in those cases we could witness social interactions between them. It was difficult to follow them while they moved on the ground because of the dense bush. The best method at present for both observation and habituation of chimpanzees might be to monitor the phenological status of food trees and wait near fruiting trees.

\section{3: Preliminary results on the socio-ecology of Ndoki chimpanzees}

Several results from the Guga and Djinji study appear quite interesting, though the available data is not sufficient to fully reveal the socio-ecology of the Ndoki chimpanzees (for details see references). I have outlined some of these results below.

(a) As at other sites the main food for chimpanzees is basically fruit (2). The fibrous parts of plants (leaves, flowers, bark and pith), insects, birds and terrestrial mammals are also eaten. The chimpanzees will hunt to get meat (Kuroda et al. in press)

(b) Just like the eastern chimpanzees (Pan $t$. schweinfurthii), the chimpanzees of Ndoki form temporary subgroups or parties with changing membership. The males seem more cohesive than the females. The existence of a "unit group" with stable membership has not yet been confirmed.

(c) The density of chimpanzees at the study site is very high, and the socionomic sex ratio does not seem skewed in favor of females as reported for previous studies at other sites.

(d) There is evidence to show that the chimpanzees use two different types of tools in combination to extract termites from their nests: a wooden stick is used to dig holes in the mound, and then a "brush" made of (e.g.) the modified stems of Marantaceae herbs is used to "fish" for termites (3). The stick is reused several times.

(e) There is considerable overlap of plant food items between chimpanzees and sympatric gorillas, although gorillas basically depend on fibrous foods $(2,4)$. Chimpanzees and gorillas might be in competition for plant food although there was no direct evidence of this. Both species were observed to feed together on several occasions in the same fruiting tree without aggression.

\section{References}

1. Nishihara, T and Fay, J M. 1996. The present progress of primatological research and conservation activities in the Nouabale-Ndoki National Park, Congo. Primate Eye 59, 2639.

2. Moutsambote, J M, Yumoto, T, Mitani, M, Nishihara, T, Suzuki, S and Kuroda, S: 1994 . Vegetation and list of plant species identified in the Nouabale-Ndoki Forest, Congo. Tropics 3, 277-294.

3. Suzuki, S, Kuroda, S and Nishihara, T. 1995. Tool-set for termite fishing by chimpanzees in the Ndoki Forest, Congo. Behaviour 132,219-235.

4. Kuroda, S, Nishihara, T, Suzuki, S and Oko, R. 1996. Sympatric chimpanzees and gorillas in the Ndoki forest, Congo. In Great Ape Societies. McGrew et al (eds.). pp. 7181.

*Author's address

Laboratory of Human Evolution Studies

Department of Zoology, Faculty of Science, Kyoto University

Sakyo, Kyoto, 606-01 Japan

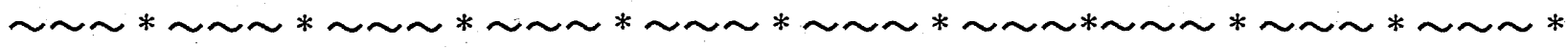

